Gestão e Desenvolvimento, 22 (2014), 55-72

\title{
A PRÁTICA DA GESTÃO EMPRESARIAL: UM ESTUDO DE CASO DA UDI-LABOFLOR CENTRO DE EXAMES MÉDICOS
}

\author{
Cícero Eduardo de Sousa Walter
}

\begin{abstract}
Resumo: Na medida em que uma start-up começa a crescer surge uma miríade de decisões que devem ser tomadas diariamente, impedindo a micro gestão característica dessas empresas no início da atividade. A resposta seria criar uma organização com uma gestão empresarial de forma sistemática, organizada e intencional. Com base nesse argumento decidimos, por meio deste estudo de caso, num primeiro momento avaliar as práticas de gestão empresarial da UDI-Laboflor Centro de Exames Médicos, incorporando as variáveis cultura organizacional $e \quad o$ desenvolvimento de estratégias competitivas e posteriormente avaliar o nível de consenso que há entre os meios e fins para que a empresa possa realmente funcionar em uníssono. Os dados foram recolhidos por meio de observações assistemáticas, na condição de consultor externo, e por meio da aplicação de um inquérito semiestruturado aos colaboradores. Os resultados apontaram para a adoção de práticas incipientes de gestão empresarial.
\end{abstract}

Palavras-chave: Gestão empresarial. Cultura Organizacional. Estratégias Competitivas. Consenso.

\section{THE PRACTICE OF CORPORATE MANAGEMENT: A CASE STUDY OF UDI-LABOFLOR MEDICAL EXAMS CENTER}

\begin{abstract}
Insofar as a start-up begins to grow comes a myriad of decisions that must be taken daily, preventing micro-management characteristic of these companies in early stages. The answer would be to create an organization with a business management
\end{abstract}

\footnotetext{
* Bacharel em Administração de Empresas pela Universidade Federal do Piauí (Brasil), com mobilidade Internacional em Economia na Faculdade de Economia da Universidade de Coimbra (Portugal). E-mail: eduardowalter1990@ hotmail.com
} 
systematically organized and intentional. Based on this argument, we decided by this case study at first to evaluate the corporate governance practices of the UDI-Laboflor Testing Center Physicians, incorporating the variables organizational culture and developing competitive strategies, and then assess the level of consensus that there is between means and ends so that the company can actually work in unison. Data were collected through unsystematic observations, provided external consultant, and through the application of semi-structured questionnaire to reviewers. The results pointed to the adoption of practices fledgling business management.

Keywords: Management. Organizational Culture. Competitive Strategies. Consensus.

\section{INTRODUÇÃO}

Uma das características que nomeadamente distinguem as empresas recém-criadas dos seus pares em estádios de evolução mais avançados é a predominância do controlo da gestão nas mãos de um ou poucos executivos. No entanto, nem sempre isso é possível. Na medida em que uma start-up começa a crescer surge uma miríade de decisões que devem ser tomadas diariamente, desde a compra de materiais às concessões de descontos em produtos ou serviços, impossibilitando um gestor de se envolver com todos os processos habituais de funcionamento, ou seja, inviabilizando a micro gestão característica das start-ups no início da atividade. A resposta seria criar uma organização com uma gestão empresarial pautada na elaboração de estratégias, no desenvolvimento de vantagens competitivas e recursos humanos, com controles financeiros rígidos de forma a fazer frente aos desafios impostos tanto pelo ambiente externo à empresa quanto pelo ambiente interno. A gestão empresarial seria a prática da atividade empresarial de forma intencional. Nas palavras de Peter Drucker (1987), "o novo empreendimento necessita de aprender a agir empresarialmente e a inovar, mas precisa, sobretudo, aprender a gerir"( pg.199). Desta forma, a gestão empresarial torna-se imprescindível para que um novo empreendimento obtenha êxito. Ainda nas palavras de Peter Drucker (1987):

O novo empreendimento possui uma ideia. Poderá ter um produto ou serviço. Poderá ter vendas, e por vezes com um volume apreciável. Tem certamente custos. E poderá ter receitas e até mesmo lucros. O que ele não tem é um "negócio", um "presente" viável, operacional e organizado, no qual as pessoas saibam para onde vão, o que se espera que elas façam e que resultados se obtêm ou deveriam obter. Mas a 
não ser que o novo empreendimento evolua no sentido de se transformar numa empresa e se assegure de que é "gerido", não conseguirá sobreviver, por muito brilhante que a ideia empresarial seja, por mais capital que atraia, por melhores produtos que tenha e até por maior que seja a procura desses produtos.( pg.199)

No seu livro Inovação e gestão: uma nova conceção de estratégia de empresa (1987), Peter Drucker discute a gestão empresarial de um novo empreendimento baseando-a em quatro fatores básicos: orientar a organização para o mercado, possuir providência financeira, ter uma boa equipa de gestão e determinar o papel do fundador.

Uma organização orientada para o mercado é aquela que, de acordo com Drucker (1987), "incorpora práticas sistemáticas que lhe recordem que um 'produto' ou um 'serviço' é definido pelo cliente, não pelo fabricante” (p. 204), caso contrário, se não estiver desde o início orientado para o mercado, ainda segundo esse autor, "a única coisa que provavelmente conseguirá criar é um mercado para um concorrente"(p.203), relativamente à providência financeira, um novo empreendimento deve planear as suas necessidade de capital de forma a enfrentar os desafios relativos à necessidade de crescimento, enquanto que uma equipa de gestão é o elemento que fornece o equilíbrio para o novo empreendimento, devendo ser constituída mesmo antes de a organização sentir necessidade desta. Não obstante a isso, o papel do fundador deve ser visto de forma evolutiva, cabendo a este perguntar-se em que poderá contribuir, tendo em vista que a organização requer novas capacidades à medida que cresce.

Partindo da conceção de gestão empresarial de Peter Drucker, apresentada na obra supracitada, e sabendo da importância desta para diversas organizações, quer sejam de serviços públicos, grandes organizações ou novos empreendimentos, decidimos por meio deste artigo, num primeiro momento, avaliar as práticas de gestão empresarial da UDI Laboflor Centro de Exames Médicos através de um estudo de caso, incorporando a análise de duas outras dimensões que, a nosso ver, assumem uma importância fundamental na construção de uma organização sustentável: a formação de uma cultura organizacional e $\mathrm{o}$ desenvolvimento de estratégias competitivas deliberadas, e posteriormente aplicar a metodologia desenvolvida pelos Professores Clayton M. Christensen, Matt Marx e Howard Stevenson da Harvard Business School, denominada "As ferramentas da cooperação e mudança", publicada na Harvard Business Review em 2009, para alinhar toda a organização na 
consecução dos seus objetivos, tendo em vista que a mesma precisa funcionar em uníssono para que isso possa realmente concretizar-se, para identificar a atual configuração da empresa em relação ao alinhamento organizacional entre os meios e fins pretendidos.

Para isso deve-se:

Descrever como a empresa em estudo desempenha a prática da gestão empresarial, evidenciando aspetos tais como a sua atual posição em relação à gestão de pessoal, gestão de capital e o seu posicionamento estratégico ${ }^{\dagger}$.

$\mathrm{O}$ artigo está estruturado em quatro secções, além da introdução. $\mathrm{Na}$ segunda secção são apresentados os principais conceitos que norteiam a gestão empresarial, a cultura organizacional, o conceito de estratégias deliberadas e de estratégias competitivas ou de negócios conjuntamente com a obtenção de vantagens competitivas. Em seguida são apresentados os procedimentos metodológicos usados e por fim, são apresentados os resultados obtidos através da análise do caso prático.

\section{REFERÊNCIAL TEÓRICO}

\subsection{A Prática da Gestão Empresarial}

Drucker (1987) assinala que a atividade empresarial baseia-se sempre nos mesmos princípios, quer o empresário seja uma grande instituição estabelecida, quer seja um indivíduo que está a montar o seu próprio negócio. Pouca ou nenhuma diferença há entre o empresário ser uma instituição estatal ou não estatal. As regras são em grande parte as mesmas, coisas que dão ou não dão resultado são em grande parte idênticas.

No entanto, a empresa estabelecida enfrenta problemas, limitações e pressões diferentes dos do empresário que trabalha por conta própria, e precisa de aprender coisas diferentes. Para pôr as coisas de um modo simplista, a empresa estabelecida sabe gerir, mas precisa de aprender a agir empresarialmente e a inovar. Também a instituição de serviços públicos enfrenta problemas diferentes, tem diferentes necessidades de aprendizagem, e é propensa a cometer erros diferentes. E o novo empreendimento precisa de aprender a agir empresarialmente e a inovar, mas precisa, sobretudo, de aprender a gerir (Drucker,1987).

\footnotetext{
$\dagger$ Ainda segundo Peter Drucker, no seu livro Inovação e Gestão: uma nova concepção de estratégia de empresa (1987), as duas áreas críticas que estão presentes em todas as organizações são a gestão de pessoal e a gestão de capital.
} 


\subsubsection{A gestão empresarial de um novo empreendimento}

Para uma organização estabelecida, seja ela empresa ou instituição de serviços públicos, a palavra-chave na expressão "Gestão empresarial" é "empresarial". Para o novo empreendimento, ela é "gestão". Na empresa estabelecida, é o estabelecido que é o principal obstáculo à capacidade empresarial. No novo empreendimento é a sua ausência (Drucker,1987).

Na conceção de Drucker (1987) a gestão de um novo empreendimento, deve pautar-se por quatro elementos básicos: orientar a organização para o mercado, possuir providência financeira, formar uma equipa de gestão e determinar o papel do fundador.

Uma organização orientada para o mercado é aquela que compreende um simples axioma do Marketing que, segundo Drucker (1987), é entender que "as empresas não são pagas para transformar os clientes. São pagas para os servir" (p.204), ou seja, as empresas devem posicionar-se de forma a considerar as necessidades dos clientes como input principal para o desenvolvimento dos produtos e serviços, e não voltar-se para o produto de forma que o mesmo tenha fim em si mesmo. No que tange a providência financeira, o novo empreendimento deve planear as sua necessidades de capital para as suas operações diárias e para o crescimento. A providência financeira ajuda a empresa a evitar as crises financeiras que, nas palavras de Drucker (1987), "é a maior ameaça ao novo empreendimento no estágio seguinte do seu crescimento" (p.204), marcada sempre pela falta de liquidez, impossibilidade de obter capital e perda do controlo sobre contas a receber e despesas existentes. Corroborando com a ideia de Drucker (1987), Arthur Rock (2002) afirma que a gestão de um novo empreendimento necessita de uma boa equipa de gestão, pois, "como empreendedor, você não pode dar-se ao luxo de cometer erros porque não tem o tempo e recursos necessários para recuperar-se. Grandes corporações podem viver com atrasos e recuos nos trabalhos mal feitos; numa situação de start-up, é melhor estar certo desde a primeira vez"(p.136).

Relativamente ao papel dos fundadores, os mesmos devem desenvolver continuamente novas capacidades e questionar-se em que podem contribuir para que a empresa possa continuar em passos largos rumo ao crescimento. 


\subsection{Cultura Organizacional}

Uma cultura organizacional é a característica que diferencia o modus operandi $^{*}$ de uma empresa das demais, reflete os seus valores, e como os funcionários percebem esses valores e incorporam-nos nas suas atividades quotidianas. Segundo Cunha et al ( 2006), "a cultura organizacional é definida de acordo com a perceção que se tem dos colaboradores", podendo a mesma refletir valores como a competição, na qual a relação entre organização e colaboradores é tida como uma mera transação comercial (o que ainda, segundo o autor supracitado, pode ser definida como uma organização como mercado), ou uma organização como comunidade, caracterizada pela cooperação, colaboração e pelo senso de pertença a um determinado grupo de trabalho. A cultura organizacional pode ser entendida como a personalidade da empresa, uma estrutura intangível que deve guiar a empresa na consecução de seus objetivos, sendo assim, a mesma deve ser previamente elaborada, sob pena de se formar de forma arbitrária e não refletir os valores da organização, como afirma o professor Amar Bhide (1996), licenciado da Harvard Business School:

Quando os empreendedores negligenciam a articulação de normas organizacionais e, em vez disso, contratam empregados principalmente pelas suas habilidades técnicas e credenciais, as suas organizações desenvolvem uma cultura por acaso, e não por planeamento. As personalidades e valores da primeira leva de empregados moldam uma cultura que pode não servir aos objetivos e estratégias dos fundadores. Uma vez que uma cultura seja estabelecida, é difícil mudá-la (p.27)

Outro fator que explica a importância da elaboração de uma cultura sólida é o fato desta apoiar o desenvolvimento e implementação de estratégias. Como sugere Amar Bhide (1996), "a cultura de uma organização em evolução exerce profunda influência sobre a forma pela qual pode desenvolver e implementar sua estratégia" (p.26).

Uma estratégia bem elaborada e executada é provavelmente o caminho mais acertado para a sustentabilidade de um negócio, quer seja uma startup em início de atividades ou uma empresa já consolidada. Geralmente, explica-se as muitas bancarrotas no mundo empresarial por três motivos ligados à estratégia: falta de uma estratégia, estratégias parcialmente implementadas, ou, uma estratégia mal concebida. Todavia, a formulação

\footnotetext{
\$ Significa a forma como as tarefas são desempenhadas para atingir o objetivo da empresa, quer seja ofertar produtos ou serviços.
} 
de uma estratégia para uma start-up pode ser um fator crucial de sobrevivência, como afirma o professor Amar Bhide (1996):

Formular uma estratégia sólida é mais fundamental para uma empresa nova do que resolver questões de contratação, projetar sistemas de controlo, ajustar hierarquias ou definir o papel do fundador. Empreendimentos com base em uma boa estratégia podem sobreviver à confusão e uma liderança ruim, mas sofisticados sistemas de controlo e estruturas organizacionais não podem compensar uma estratégia fraca (p.17)

A cultura organizacional pode ser considerada como um elemento estratégico, pois, ao contrário de sistemas e outras estruturas organizacionais, a mesma não pode ser facilmente copiada, muitas vezes sendo objeto de ambiguidade causal, que segundo Martín e López (2007) "é uma situação na qual os concorrentes não tem conhecimento de quais fatores são os responsáveis pelo bom desempenho de uma empresa"(p.245). Não obstante a isso, uma cultura organizacional bem definida, alinhada a um estratégia bem elaborada pode fornecer a uma empresa uma relativa vantagem competitiva, pois os colaboradores terão uma visão de onde a organização quer estar e farão o possível para chegar lá.

\subsection{O Conceito de Estratégias Deliberadas}

As empresas movem-se hoje em dia num contexto extremamente difícil em que são muitos e muito valiosos os competidores, em que já não basta criar uma empresa para ter êxito, nem se quer basta saber como vender. A concorrência entre as empresas é cada vez mais aberta e dura. O entorno é enormemente mutável e turbulento. As fronteiras económicas entre os países vêm desaparecendo (Martín e López, 2007).

Neste contexto, é cada vez mais necessário que os empresários e os altos diretores das empresas dediquem um maior esforço e análise a elaboração e escolha da estratégia mais adequada para responder aos desafios do entorno e tornar assim a empresa mais competitiva nesse contexto. Poderia afirmar-se que todas as empresas têm ou seguem uma estratégia embora, em muitas delas, permaneça implícita na mente do empresário ou da direção geral. O esforço para torna-la explícita, analisala e racionaliza-la pode ser muito valioso para melhorar a posição competitiva da empresa e, em consequência, seus resultados (Martín e López, 2007). 
Uma estratégia deliberada é aquela que segundo Martín e López (2007) baseia-se "num processo racional e estruturado, controlado pela alta direção para elaborar uma estratégia que será posta em prática através de um plano relativamente predeterminado"(p.66). Para Whittington (2002) esta é a conceção clássica de estratégia ${ }^{\S}$, nas suas palavras:

É o processo racional de cálculos e análises deliberadas, com o objetivo de maximizar as vantagens de longo prazo. Se houver um esforço em reunir informações e aplicar as técnicas apropriadas, tanto o mundo exterior quanto a empresa, tornam-se previsíveis e maleáveis, moldados de acordo com os planos cuidadosos da gerência executiva. Para os clássicos, dominar os ambientes interno e externo exige um bom planeamento. A estratégia é importante nessa análise racional, as decisões objetivas fazem a diferença entre o sucesso prolongado e o fracasso (p.03).

\subsection{Estratégias Competitivas ou de Negócios e a Construção de Vantagens Competitivas}

Habitualmente podem-se considerar no pensamento estratégico três níveis de definição de estratégias, correspondente aos distintos níveis hierárquicos na organização, a cada um dos quais se atribuem diferentes competências acerca da tomada de decisões. Estes três níveis são: estratégias corporativas ou de empresas, estratégias competitivas ou de negócios e estratégias funcionais (Martín e López, 2007).

De acordo com Martín e López (2007), as estratégias de nível corporativo ou de empresa tratam de "fixar a orientação básica da empresa em seu conjunto"(p.46), que envolvem as decisões tais como entrar em novos mercados ou comprar outras empresas, enquanto que, as estratégias de nível competitivo ou de negócios determinam "como competir melhor num conjunto de atividades, negócios ou unidades estratégicas de negócio" (p.46) e por fim, as estratégias funcionais são aquelas que se concentram em "como utilizar e aplicar os recursos e habilidades dentro de cada área funcional da empresa"(p.47).

Neste trabalho elucidaremos apenas a estratégia de nível competitivo, pois segundo os autores supracitados, "A criação e a manutenção de uma vantagem competitiva e a criação, melhora e exploração de recursos e capacidades valiosos são elementos chave desse nível” (p.46),

\footnotetext{
${ }^{\S}$ No seu livro $O$ que é estratégia, publicado em 2002, Richard Whittington descreve mais três abordagens sobre o conceito de estratégia: a abordagem sistémica, evolucionista e processual. Devido à relevância da abordagem clássica para o trabalho em questão não discutiremos neste artigo as demais conceções de estratégia.
} 
corroborando substancialmente com a proposta da criação de uma cultura organizacional como elemento estratégico ${ }^{* *}$.

Uma vez que uma empresa escolheu a indústria em que irá competir ${ }^{\dagger \dagger}$, deve determinar como irá competir nessa indústria, de forma a construir uma vantagem competitiva. De acordo com Martín e López (2007), uma vantagem competitiva faz referência a uma "situação de superioridade ou condições favoráveis que uma coisa tem sobre outra" (p.267), ou seja, "o conceito de vantagem competitiva entende-se como qualquer característica da empresa que a diferencia das demais, colocando-a numa posição relativa de superioridade para competir" (p.267). Dentro deste prisma, uma empresa pode adquirir vantagem competitiva mediante aspetos externos, como a capacidade de flexibilidade ao ajustar-se ao entorno ou pela capacidade de prognóstico, que seria identificar e antecipar-se às mudanças (Martín e López, 2007). Ou por aspetos internos, como a vantagem competitiva em custos ou pela vantagem competitiva na diferenciação de produtos.

Segundo Martín e López (2007), uma vantagem competitiva em custos ocorre quando uma empresa tem "custos inferiores ao dos seus concorrentes para um produto ou serviço semelhante ou comparável em qualidade" (p.276-277), enquanto que uma vantagem em diferenciação de produtos uma empresa oferece um produto ou serviço que "sendo comparado com o de outra empresa, tem certos atributos que fazem com que o mesmo seja percebido como único para os clientes"(p.285).

De acordo com o guru da estratégia Michael Porter, 1982, citado por Martín e López (2007), uma empresa pode adotar duas estratégias competitivas genéricas baseadas nessas vantagens competitivas e que consequentemente a deixe em relativa superioridade em relação às demais

\footnotetext{
Martín e López discutem no seu livro La Dirección Estratégica de la Empresa:Teoría y Aplicaciones( 2007), que tão importante quanto o desenvolvimento de uma boa estratégia é a sua implementação, e que para tal a organização precisa desenvolver dois mecanismos de implantação: um suporte organizacional, no qual privilegiam-se a liderança e a cultura organizacional e um sistema de apoio, que trata da criação de sistemas de informações que facilitem o acompanhamento da implementação da estratégia escolhida. Nesse caso, uma cultura organizacional bem definida facilita tanto o desenvolvimento das estratégias quando a sua posterior implementação.

† Abell (apud Martín e López, 2007), define a escolha da indústria por meio das seguintes perguntas: Quais clientes atender, quais necessidades satisfazer e com qual tecnologia?
} 
empresas da indústria, são elas: uma estratégia de liderança em custos e de diferenciação.

A estratégia de liderança em custos consiste em oferecer produtos ou serviços com uma estrutura de custos menor do que a dos concorrentes, podendo oferecer produtos ou serviços com um preço baixo, enquanto que a de diferenciação implica em fazer com que o produto ou serviço oferecido seja visto pelos consumidores como único, de forma que os mesmos fiquem propensos a pagar um preço superior à concorrência por esse fator de diferenciação.

\section{MÉTODO}

O presente trabalho trata da criação de conhecimento do particular para o geral, caracterizando-se como um método indutivo, e com uma abordagem tanto qualitativa quanto quantitativa, por meio do estudo de caso das práticas de gestão empresarial da UDI-Laboflor Centro de Exame Médicos, caracterizado como um estudo exploratório, que segundo Gil, 1991, citado por Silva e Menezes (2001) "visa proporcionar maior familiaridade com o problema com vista a torná-lo explicito ou a construir hipóteses" (p.21), baseado na análise de dados primários.

Segundo Silva e Menezes (2001), o estudo de caso "envolve o estudo profundo e exaustivo de um ou poucos objetos de maneira que se permita o seu amplo e detalhado conhecimento" (p.21), ainda em relação ao estudo de caso, Yin (2005) o caracteriza como uma metodologia "particularmente apropriada para responder perguntas do tipo 'como' e 'por que' e é bem apropriada para gerar e construir teoria em uma área onde há poucos dados e teoria e sobre o qual o pesquisador não tem total controlo" (p.12).

Os dados foram recolhidos por meio de observações assistemáticas, que segundo Silva e Menezes (2001), "não tem planeamento e controlo previamente elaborados"(p.33), durante o período compreendido entre Outubro de 2011 e Novembro de 2012, na condição de consultor externo, e pela aplicação de um inquérito com perguntas abertas e fechadas aos colaboradores com o intuito de predizer as suas predisposições em relação ao funcionamento da organização, como a mesma influencia e é influenciada pelos mesmos.

A análise dos dados foi feita pela técnica da análise de conteúdo, que de acordo com Patton, 1998, citado por Dellagnelo e Silva (2005) é "um processo de identificação, codificação e categorização de dados primários em informações"(p.99).

O estudo possui como limitações a dificuldade na validação externa e a transferibilidade, pois para tal, deve-se atentar para os contextos em que se 
inserem as demais organizações do segmento estudado, sendo que cada uma possui as suas particularidades.

\section{ESTUDO DE CASO}

\subsection{Identificação da Empresa}

A empresa que servirá de base para a realização deste estudo de caso é a UDI- Laboflor Centro de Exames Médicos uma empresa familiar que presta serviços de exames de diagnostico por imagem para a população florianense, regiões vizinhas e para a maioria das empresas de planos de saúde aceitos no estado do Piauí, situada na cidade de Floriano-PI, Brasil, originária de uma diversificação não relacionada do Laboflor Centro de Exames Médicos, a qual se faz importante a apresentação de um breve histórico que deu origem à UDI.

Em 1976 nasce em Floriano o Laboratório de Análises Clinicas de Floriano, o Laboflor, do Bioquímico José Bruno dos Santos Filho. No ano de 1978 foi implantado o departamento de bacteriologia, levando o Laboflor a ser o pioneiro em exames bacteriológicos da cidade de Floriano. Em 1994 é inaugurada mais uma unidade do Laboflor na cidade de Itaueira-PI, o primeiro laboratório de análises clínicas dessa cidade. Em 2005 o Laboflor apresenta as suas novas instalações na cidade de Floriano e inaugura mais uma unidade na cidade de Itainópolis-PI, Em 2008 o Laboflor inaugura mais uma unidade na cidade de Teresina-PI, sendo a quarta unidade em todo o estado do Piauí, ao mesmo tempo inicia-se as obras do maior e mais ambicioso empreendimento do Laboflor na cidade de Floriano, que associa às suas instalações o mais moderno e completo setor de radiologia e diagnóstico por imagem da cidade sob a supervisão do Dr. Bruno Maia, médico radiologista e filho do Dr. José Bruno. No ano de 2009 o Laboflor introduz a primeira máquina de Tomografia computadorizada da cidade de Floriano, inaugurando a UDI-Laboflor Centro de Exames Médicos.

\subsection{Práticas de Gestão Empresarial Adotadas pela Empresa}

\subsubsection{Gestão de pessoal: a perspetiva dos colaboradores em relação à empresa}

A empresa em estudo, no período em que foi realizada esta pesquisa tinha um quadro efetivo de 10 colaboradores, distribuídos entre médicos, técnicos de Radiologia, rececionistas e auxiliares de serviços gerais. Por se 
tratar de uma pequena empresa inexiste um departamento que cuide especificamente da gestão de pessoal, ficando a cargo do Administrador Geral, que por seu turno possui formação como médico-radiologista e é o próprio proprietário da clínica. Não existem documentos relativos à descrição de funções, os colaboradores assim que recrutados recebem orientações gerais de como deverão desempenhar as suas atribuições, o que por vezes causa conflitos, pois, as atribuições não estão claras o bastante. Todavia, o maior problema, segundo relatos desses mesmos funcionários seria a sobrecarga de trabalho. Segundo eles, o fluxo de atribuições é maior do que poderiam dar conta, reduzindo consideravelmente a eficiência nos seus postos de trabalho. Isso é válido tanto para a receção quanto para os serviços gerais. Ao serem perguntados sobre o grau de responsabilidade percebido em suas funções (Gráfico-1), a maioria dos colaboradores $(42,85 \%)$, respondeu que a responsabilidade é elevada.

\section{Gráfico 1}

Grau de responsabilidade percebido por cada funcionário no exercício de suas funções.

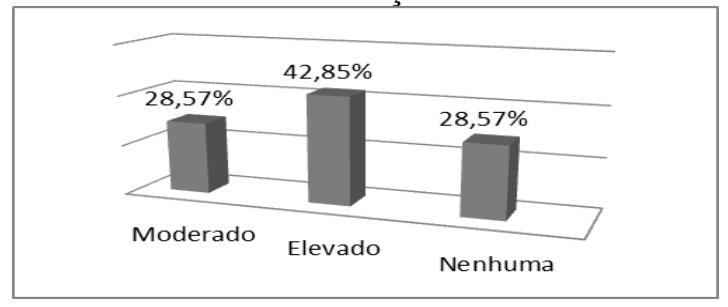

Note que há uma equiparação entre os níveis de responsabilidade percebidos como "moderado" e "nenhuma responsabilidade", que pode indicar que os colaboradores enquadrados na condição de "não possuo responsabilidade", possivelmente não fazem ideia do quão importante as suas funções são para o desenvolvimento global das atividades diárias. As suas visões estão limitadas a apenas às suas atribuições, que dessarte, os impossibilitam de enxergar e sentir que fazem parte de um todo que deve funcionar de forma orquestrada.

Outro ponto que deve ser ressaltado é a necessidade de reconhecimento (Gráfico-2). 85,71\% dos funcionários afirmam que gostam de ser reconhecidos pelo bom trabalho que desempenham, isso torna-se um problema a partir do momento que estes funcionários não recebem tal atenção. A tendência será diminuir o ritmo, uma vez que não fará 
diferença se eles se esforçarem mais, comprometendo consideravelmente o rendimento global da empresa.

Gráfico 2

Relação entre reconhecimento e realização do trabalho

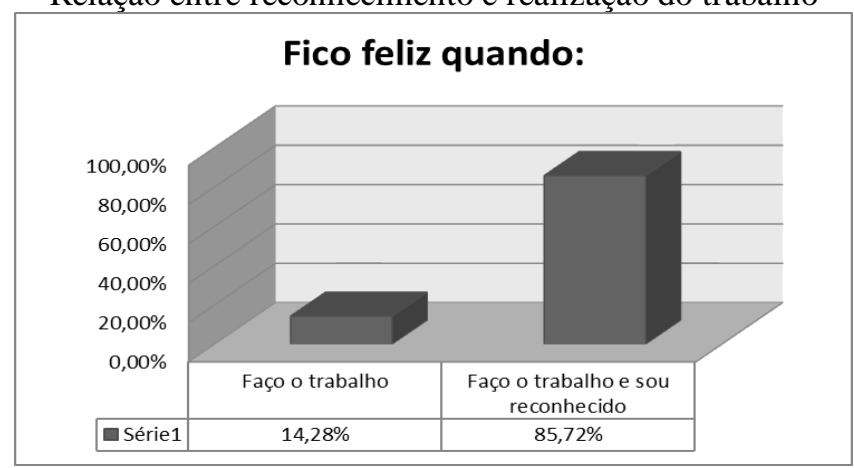

Chiavenato (2003), assinala baseado nos behavioristas que, o comportamento dos indivíduos é condicionado por fatores do ambiente. Sendo assim, uma das possíveis ações que poderiam ser usadas para dirimir problemas relacionados à necessidade de reconhecimento, seria o reforço positivo. Essa teoria prega que bons comportamentos quando incentivados e reconhecidos tendem a ser repetidos. Reconhecer um bom desempenho nem sempre está associado a recompensas salariais, um simples "ótimo trabalho" poderá resolver a questão.

\subsubsection{Gestão financeira: considerações sobre fluxos de caixa e planeamento financeiro}

No que tange à providência financeira, a empresa utiliza o acompanhamento sistemático das receitas e despesas por meio de um fluxo de caixa estruturado na planilha do Microsoft Excel, que fornece informações detalhadas diariamente e mensalmente, possibilitando a realização de análises horizontais e verticais, cálculos de margens de contribuição e do ponto de equilíbrio, bem como o desenvolvimento de gráficos de tendências para o ano vindouro. Todavia, a empresa não possui políticas financeiras que possam suprir necessidades contingentes de capital, não há reinvestimento dos "lucros" na empresa, o mesmo é quase exclusivamente retirado na condição de pró-labore. Sempre que há a necessidade de capital, a empresa recorre a empréstimos bancários. O que poderia ser utilizado em última instância, pois, no período analisado a 
empresa poderia optar pelo crescimento endógeno, utilizando apenas o seu fluxo de caixa como principal fonte de financiamento. ( $O$ índice de liquidez total da empresa no período em questão era de quase 6 para 1, ou seja, para cada $R \$ 1,00$ de despesas a empresa possuía $R \$ 6,00$ de ativos)

$\mathrm{O}$ que poderia ser altamente eficiente seria a criação de um fundo de contingência, no qual, poder-se-ia atribuir uma percentagem de 15 ou 20\% da receita bruta mensal para suprir necessidades esporádicas de capital, ou para fazer parte de um plano de crescimento em longo prazo.

\subsubsection{Posicionamento estratégico: considerações sobre o desenvolvimento e implementação de estratégias competitivas ou de negócios}

A empresa não possui uma declaração de missão, visão e objetivos definidos, tão pouco uma estratégia competitiva. A mesma está apenas na cabeça do proprietário, tornando assim obscuro os objetivos que devem ser perseguidos pelos colaboradores. Todavia, por meio da observação assistemática, poderíamos dizer que a estratégia adotada (neste caso uma estratégia emergente, que surge do choque entre o contexto e a organização) é uma estratégia de diferenciação, pautada exclusivamente na qualidade do atendimento e dos serviços prestados. Outro fator que deve ser ressaltado é o monopólio que a empresa possui na cidade de Floriano em relação ao procedimento de Tomografia computadorizada, que por sua vez, pode ocasionar a acomodação.

O facto de determinar uma missão e visão claras poderia orientar a empresa na elaboração de estratégias competitivas e consequentemente transmitir aos colaboradores o que se espera que eles façam. A empresa deveria adotar um processo de gestão estratégica, que compreende a análise estratégica, na qual avalia-se o entorno geral e específico, na busca de tendências, os pontos fortes e fracos, ameaças e oportunidades; a formulação de estratégias, que baseia-se nas análises feitas na etapa anterior e a implementação da estratégia, fazendo um ajuste organizacional entre a estratégia escolhida e a organização. A adoção da gestão estratégica poderia colocar a empresa em relativa posição de superioridade em relação aos seus concorrentes, pois, estaria mais apta a enfrentar os desafios do entorno.

\subsubsection{Cultura organizacional: considerações sobre a atual cultura corporativa}

A cultura organizacional da empresa é marcada pela indecisão. Os colaboradores não sabem para onde ir e nem o que se espera deles. 
Poderíamos afirmar que a mesma nunca foi planeada, e o que é pior, não é levada em consideração sob nenhum aspeto.

O sentimento que os colaboradores compartilham é o de que as coisas devem simplesmente ser feitas, e que os "incêndios" devem ser apagados quando surgirem. $\mathrm{O}$ senso de pertença à organização praticamente inexiste, a organização é vista como mercado, não no que tange a forma como os mesmos se comportam, que nesse caso é a competição, mas sim nas relações entre organização e colaboradores, uma relação meramente transacional. O maior problema neste tipo de relação é que os funcionários limitam-se a desempenhar apenas as funções que são pagos para desempenhar, praticamente inexistindo a motivação para tarefas extra papel.

O que poderia ser feito em relação a isso seria a criação de uma cultura organizacional decisiva, por meio da atuação da alta direção, ou dos líderes que exerçam maiores influencias nos colaboradores. Nas palavras de Charan (2008):

Quebrar uma cultura de indecisão exige um líder que pode gerar honestidade intelectual e confiança nas relações entre as pessoas. Aproveitando cada encontro com os seus subordinados como uma oportunidade para modelar um diálogo aberto, honesto e decisivo, o líder dita o tom para a organização inteira [...] Em síntese, os líderes criam uma cultura de comportamento decisivo atentando para o seu próprio diálogo, tomando cuidado com os mecanismos de interação entre as pessoas e por meio da conclusão e do feedback apropriados(p.145)

\section{OBTENDO O CONSENSO: APLICAÇÃO DAS FERRAMENTAS DE COOPERAÇÃO E DA MUDANÇA}

Uma vez que a cultura organizacional se tenha constituído por acaso, mudá-la pode ser um desafio considerável. Os colaboradores estarão profundamente arraigados a normas e hábitos que no geral impedem as empresas de desenvolverem-se. Isso é evidente na empresa em estudo. De acordo com Christensen et al (2009), "os empregadores tem uma série de ferramentas a escolher para incentivar os empregados a trabalhar em cooperação visando atingir uma meta corporativa"(p.167). Em suas palavras:

Quando as pessoas numa organização discordam sobre o que querem e como atingir os resultados desejados, as únicas ferramentas capazes de induzir a cooperação são as "ferramentas de poder", que são essencialmente variações da coerção e controlo. Se as pessoas 
quiserem a mesma coisa, mas discordarem sobre a forma de atingir o que querem as "ferramentas de liderança", como liderar pelo exemplo e o carisma, podem motivá-las a chegar a um consenso. Se as pessoas concordarem em relação ao que fazer, mas discordarem sobre o que querem, os liderem podem empregar "ferramentas gerenciais", como treinamento e sistemas de mensuração. As empresas nas quais os empregados concordam em relação a ambas as dimensões da matriz, e em geral estão satisfeitos com o status quo, têm culturas muito fortes que são difíceis de mudar. Nessas circunstâncias, só é possível mudar a direção utilizando "ferramentas culturais", como rituais e histórias(p.171)

De acordo com os autores supracitados a escolha da ferramenta está associada à avaliação do consenso na organização em dois níveis: a extensão na qual as pessoas concordam sobre o que querem, tais como os resultados que se esperam deles e, a extensão na qual as pessoas concordam sobre o que fazer, quais meios levarão aos resultados pretendidos. A figura-1 apresenta esquematicamente a aplicação das ferramentas de acordo com o nível de consenso.

Figura-1

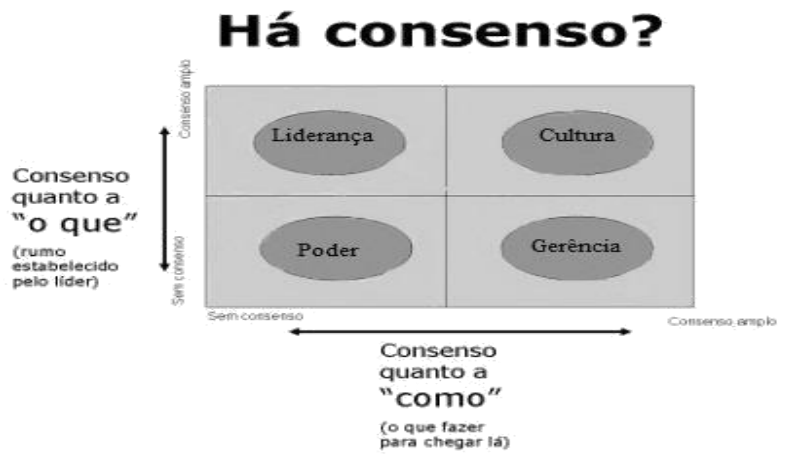

Matriz de consenso e ferramentas de cooperação e mudança

Fonte: Adptado de Christensen et al (2009)

Ao analisarmos a cultura da UDI-Laboflor, na qual os colaboradores não sabem o que se espera deles, e nem o que fazer para atingir os resultados, a ferramenta a ser utilizada seria o poder. O líder deve deixar claro o que se espera dos colaboradores e como farão para atingir os resultados, deve tornar explícitos os planos da empresa, definindo planos de ação, atribuindo responsabilidades aos colaboradores, controlando e avaliando os resultados. Em suma, a gestão deve orientar-se de cima para 
baixo, de forma a construir uma cultura organizacional orientada para o desenvolvimento da empresa e dos colaboradores, uma cultura que possa refletir a formulação deliberada de estratégias competitivas e que promova o alinhamento entre os meios e fins.

\section{CONSIDERAÇÕES FINAIS}

Como foi exposto anteriormente, a gestão empresarial deve ser uma atividade intencional e sistemática, devendo ser aplicada tanto nos novos empreendimentos quanto nas empresas estabelecidas e de serviços públicos. A prática da atividade empresarial dota uma empresa de ferramentas gerenciais para enfrentar os desafios impostos tanto pelo ambiente interno quanto externo às empresas. Além da adoção intencional da gestão empresarial, uma organização deve definir desde o princípio da sua existência a sua cultura organizacional, deve deixar claro o que se espera dos colaboradores e como farão para tingir os resultados predeterminados, deve também adotar um processo de gestão estratégica, que promova a formulação de estratégias de nível competitivo, de forma a melhor utilizar os seus recursos, os pontos fortes e mitigar as ameaças e os pontos fracos. A empresa em questão adota apenas parcial e inconscientemente a gestão empresarial, desconsiderando a importância da mesma e da gestão estratégica para o desenvolvimento de um negócio sustentável. Não possui uma cultura organizacional planejada e parece não se aperceber da importância da mesma.

Um fator que poderia estar ligado a essa posição seria a falta de um administrador profissional. Alguém que tenha as capacidades, habilidades e atitudes gerenciais para conduzir um processo de mudança dentro da empresa, alguém que tenha capacidade de prognóstico, para identificar os problemas mesmo antes de eles surgirem e adotar as ferramentas corretas para suprimir quaisquer eventuais problemas.

Ao avaliarmos a empresa por meio da matriz de consenso, percebemos que os colaboradores não têm ideia do que se espera deles e nem quais os resultados pretendidos. Dentre os desafios que a empresa terá pela frente estão o desenvolvimento de uma cultura organizacional, a implementação de uma política financeira que englobe as contingências e a preocupação com o alinhamento entre meios e fins para que a empresa possa realmente funcionar em uníssono. 


\section{REFERÊNCIAS}

Bhide,Amar. (2002), "As perguntas que todo empreendedor deve responder". Subtítulo em: Havard Business Review. Empreendedorismo e Estratégia. Rio de Janeiro: Elsevier, p.9-34.

Cunha, M.; Rego, A.; Cunha, R.; Cardoso, C. (2006), Manual de Comportamento Organizacional e Gestão, $5^{\mathrm{a}}$ ed., Lisboa: Editora $\mathrm{RH}$.

Chiavenato, Idalberto. (2003), Introdução à Teoria Geral da Administração: uma visão abrangente da moderna administração das organizações. $7^{a}$ Ed. Rio de Janeiro: Elsevier.

Charan, Ram. (2008), "Vencendo uma cultura de indecisão". Subtítulo em: Harvard Business Review. Decisões mais inteligentes. Rio de Janeiro: Elsevier, p.141-161.

Christensen, Clayton; Marx, Matt; Stevenson, Howard. (2009), "As ferramentas da cooperação e da mudança". Subtítulo em: Harvard Business Review. Renovação da Estratégia. Rio de Janeiro: Elsevier. p.165-185.

Drucker, Peter. (1987), Inovação e Gestão: uma nova concepção de estratégia de empresa. Lisboa: Editorial Presença.

Dellagnelo, Eloise H; Silva, Rosimeri C. (2005), "Análise de conteúdo e sua aplicação em pesquisa na Administração". Subtítulo em: Vieira, Marcelo; Zouain, Debora (Org.). Pesquisa Qualitativa em Administração: teoria e prática. Rio de Janeiro, Editora FGV. p. 97118.

Martín, Luis A.; López, José M. (2007), La Dirección Estratégica de la Empresa: teoria y aplicaciones. Pamplona: Editorial Aranzadi.

Rock, Arthur. (2002), "Estratégias versus táticas de um capitalista". Subtítulo em: Harvard Business Review. Empreendedorismo e Estratégia. Rio de Janeiro: Elsevier.p.131-142.

Silva, Edna Lúcia; Menezes, Estera M. (2001), Metodologia da pesquisa $e$ elaboração de dissertação.- $3^{\mathrm{a}}$ ed.rev. atual- Florianópolis: Laboratório de Ensino a Distância da UFSC.

Whittington, Richard. (2002), O que é estratégia. São Paulo: Pioneira Thomson Learning.

Yin, Robert K.( 2005) Estudo de Caso: Planejamento e Método. - 3 ed. Porto Alegre, RS. Editora Bookman. 